\title{
SURVEY ON THE USE OF SYNTHETIC FOOD COLORS IN FOOD SAMPLES PROCURED FROM DIFFERENT EDUCATIONAL INSTITUTES OF KARACHI CITY
}

\author{
Nida Saleem ${ }^{1 *}$, Zahida N Umar ${ }^{1}$, Seema Ismat Khan ${ }^{1}$ \\ ${ }^{1}$ Department of Food Technology, Food and Marine Resources Research Centre, PCSIR Laboratories Complex, Karachi, Pakistan
}

\section{ABSTRACT}

The present study was carried out to find the type of food colors added to various food products especially those vended at or near different educational institutes of Karachi city. Different types of food items were analyzed for isolation and identification of the added synthetic food colors. The majority of branded food items contained permitted colors however some foods manufactured locally, contained non-permitted colors. About $11 \%$ branded and $44 \%$ unbranded food items, respectively, were found with not permitted colors for human consumption. Similarly, $4 \%$ branded and $30 \%$ unbranded beverages were found unfit due to the presence of prohibited colors. Incidences of the use of non-permitted food colors were higher in case of unorganized food makers. Constant vigilance is needed to ensure that the local manufacturers comply with the regulations of food colors not only in terms of non-permitted food colors but also about the control and limits of permitted food colors. Moreover, consumption of colored food items should also be controlled by making the society aware of the hazardous effects of food colors.

Keywords: synthetic food colors, consumption, branded food items, hazardous effects

\section{BACKGROUND}

In Pakistan, like most developing countries, both the industrial and non-industrial sectors are engaged in food processing activities. The industrial sector is subjected to quality checks whereas the non-industrial sector, by its nature, is outside of this realm, resulting in increased production of sub-standard food products compromising human health to serious diseases, leading to an indirect financial burden on the national economy. Food products including bakery products like cakes, snacks, confectionaries and other food items, produced in non-industrial sector are two to three times of that produced in industrial sector [1-5].

Food colors are the major source of food intoxication and surveys have been conducted to determine the presence of non-permitted food colors in different food products [6]. It is an instinct phenomenon that humans, specifically

\author{
*Corresponding Address \\ Nida Saleem \\ Department of Food Technology \\ Food and Marine Resources Research Centre \\ PCSIR Laboratories Complex \\ Dr. Salimuzzaman Siddiqui Road \\ Off University Road, Karachi-75280 \\ Pakistan
}

young children are always attracted to food and drinks bearing pleasant colors, so addition of attractive colors can definitely enhance the appetizing value and the palatability of food and drink for the consumers. Most manufacturers use variety of colors in their bakery products. Similarly, colors are often used in the manufacturing of soft drinks, various kinds of toffees, ice-creams, jams and jellies etc, by the big manufacturers as well as both street vendors. Even house wives use dyes to color rice and other dishes, mainly to give them a more appetizing look. It has been suggested that consumption of foods containing color additives could sometimes lead to harmful effects [7].

Synthetic colors are reliable and economical for restoring the original shade of the foods (that would otherwise be virtually dull) compared to the natural colorants which are expensive, less stable, and possess lower tinctorial power $[8,9]$. The use of synthetic colors by the food processing industry is increasing because they are considered as important adjuncts.

Many unpacked foods consisting of snacks, colored candies, bakery products, chewing gums, colored ice balls and cold drinks containing prohibited colors and toxic chemicals or additives in quantities higher than the toxic levels 
are vended outside educational institutes and other areas inhabited by low income populations and there is no quality control on such products. The use of non-permitted colors is known to cause adverse effects in experimental animals [10-12] and in humans [13-15]. Repeated exposure to even the permitted synthetic colors may be hazardous 1, 21. Many of these dyes are originally derived from coal tar, commonly called coal-tar dyes, contain the azo group. By definition, colored chemicals are active chemicals hence requiring greater care than bland additives such as emulsifiers.

Table 1: List Of Permissible Food Colors According To Pakistan Pure Food Rules (1965)

\begin{tabular}{|c|c|c|c|}
\hline S.\# & $\begin{array}{l}\text { Permitted Food } \\
\text { Colorants }\end{array}$ & S. \# & $\begin{array}{l}\text { Permitted Food } \\
\text { Colorants }\end{array}$ \\
\hline 1 & $\begin{array}{l}\text { Food Blue } 1 \\
\text { (Indigo Carmine) }\end{array}$ & 10 & $\begin{array}{l}\text { Food Yellow } 3 \\
\text { (Sunset yellow) }\end{array}$ \\
\hline 2 & $\begin{array}{l}\text { Food Blue } 2 \\
\text { (Brilliant Blue) }\end{array}$ & 11 & $\begin{array}{l}\text { Food Yellow } 4 \\
\text { (Tartrazine) }\end{array}$ \\
\hline 3 & $\begin{array}{l}\text { Food Blue } 4 \\
\text { (Indanthrone) }\end{array}$ & 12 & $\begin{array}{l}\text { Food Brown } 1 \\
\text { (Brown F.K) }\end{array}$ \\
\hline 4 & $\begin{array}{l}\text { Food Blue } 5 \\
\text { (Patent Blue V) }\end{array}$ & 13 & $\begin{array}{l}\text { Food Brown } 2 \\
\text { (Choc. Brown) }\end{array}$ \\
\hline 5 & $\begin{array}{l}\text { Food violet } 2 \\
\text { (Violet } 6 \mathrm{~B})\end{array}$ & 14 & $\begin{array}{l}\text { Food Brown } 3 \\
\text { (Choc. Brown H.T) }\end{array}$ \\
\hline 6 & $\begin{array}{l}\text { Food violet } 3 \\
\text { (Violet BNB) }\end{array}$ & 15 & $\begin{array}{l}\text { Food Red } 1 \\
\text { (Ponceau SX) }\end{array}$ \\
\hline 7 & $\begin{array}{l}\text { Food Green } 1 \\
\text { (Sulpho green } 2 \mathrm{BA})\end{array}$ & 16 & $\begin{array}{l}\text { Food Red } 9 \\
\text { (Amaranth ) }\end{array}$ \\
\hline 8 & $\begin{array}{l}\text { Food Green } 2 \\
\text { (Acid Brilliant 3) }\end{array}$ & 17 & $\begin{array}{l}\text { Food Red } 14 \\
\text { (Erythrosine B.S) }\end{array}$ \\
\hline 9 & $\begin{array}{l}\text { Food Green } 3 \\
\text { (A.F Green No.3) }\end{array}$ & 18 & $\begin{array}{l}\text { Food Black } 1 \\
\text { (Black B.N) }\end{array}$ \\
\hline
\end{tabular}

In recent years, these colors have been subjected to rigid toxicological examination with the result that most of the countries now have a very short list of permitted colors and/or additives. Different countries permit different synthetic food colors. The USA permits seven food colors, including Fast Red (which is prohibited in India), Iran and Australia permit thirteen each and in the European Union (EU) sixteen synthetic food colors are permitted. European countries have been harmonizing the regulations, and most of the controls on colorings in food items from EU directives. Each country is attempting to review these controls by surveillance work [17]. According to Pakistan pure food rules (1965), eighteen synthetic and five natural food colors are permitted in Pakistan (Table 1) in specified food items. The use of black and brown dyes is completely banned in developed countries as they contain harmful ingredients. The maximum limit of permissible colors to be added in any food shall be $0.1 \mathrm{~g} / \mathrm{Kg}$ of food as consumed. The Acceptable Daily
Intake (ADI) has been defined as the amount of a substance that can be consumed everyday throughout the lifetime of an individual without any appreciable health effects [18]. Even permissible artificial colors, if consumed indiscriminately are not safe. The ADI of erythrosine was reduced from 2.5 to $0.1 \mathrm{mg} \mathrm{kg}^{-1}$ body-weight, as it produced effects on thyroid function in short-term studies in rats [19].

Keeping in view the hazards of coloring compounds, a research study was conducted to find out the percentage of consumption of adulterated or substandard food products by general public particularly young school children. Snack foods, colored candies, bakery products, chewing gums, toffees, colored ice balls, colddrinks and ice-creams vended outside the educational institutes, usually contain non-food grade colors, thus compromising the health of people to serious diseases.

\section{MATERIALS AND METHODS}

Samples of different food items and beverages were collected from different educational institutes, both from the canteens and vending carts outside the schools, located in different areas of Karachi. These included all types of areas ranging from slums i.e. those inhabited by low income populations, middle class, upper middle class, to posh areas, resided by rich and wealthy people. The government and private both kinds of institutions were included in the study in order to get a true picture of the metropolis so far as the quality of the food products available to people especially young children is concerned. Samples were categorized as branded i.e. having some labels and trade names and unbranded having no labels either unpacked or packed by the vendors.

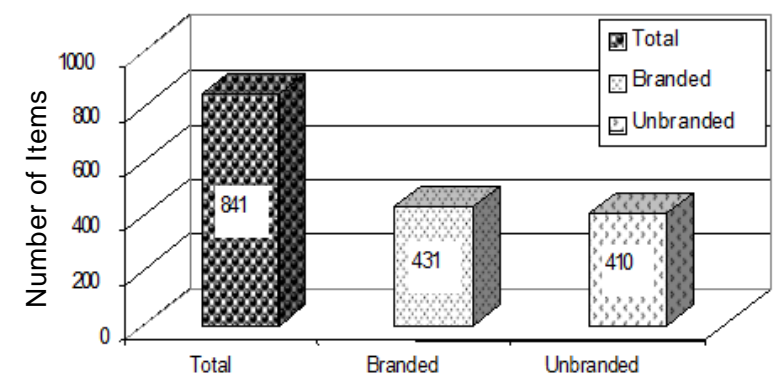

Figure 1. Survey of Colored food Items

A total of 841 samples of different food items such as confectioneries, ice balls, chewing gums and bakery products were analyzed for their 
colors out of which 431 were branded and 410 were unbranded items. Similarly 1060 beverages analyzed for their colors consisted of 349 branded and 711 unbranded items. Food samples were collected in polythene bags while those of beverages were collected in sterilized screwcapped glass bottles. Insulated ice chest with ice packs was used for collection of samples (Fig. 1 and 2).

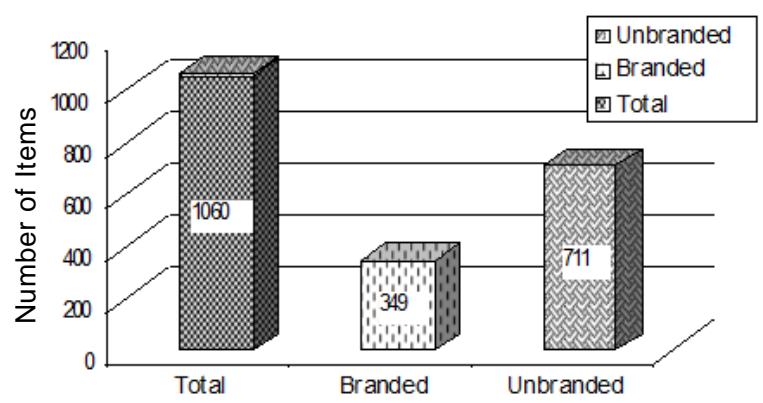

Figure 2. Survey of Colored Beverages

The collected samples were labeled with date and lab code. The other necessary information of the samples, like area or location of school, collection point, etc was also recorded. Colors were extracted $[20,21]$ from all the samples and then analytical techniques were used to analyze the colors qualitatively and quantitatively.

\section{Color Extraction}

All the collected samples were tested for their colors against the available standards for food and textile colors (Table 2 and 3). Colors were extracted from different food samples by dissolving solid and semi solid food items in water before isolation of colors whereas liquid food samples were used directly [21,22].

Table 2. List Of Standard Food Colors

\begin{tabular}{ll}
\hline S. \# & Food Color Additives \\
\hline 1 & Erythrosine \\
2 & Brilliant Blue FCF \\
3 & FD\&C Blue 2 powder \\
4 & Patent Blue V powder \\
5 & Tartrazine \\
6 & Sunset Yellow FCF \\
7 & Ponceau 4R \\
8 & FD\&C Green No. 3 \\
9 & Indigo carmine \\
10 & Acid Blue 9 \\
11 & Amaranth \\
12 & Black PN powder \\
13 & Bluish Red \\
14 & Brown HT powder \\
15 & FD\&C Red No. 4 \\
16 & Acid Violet 49 \\
\hline
\end{tabular}

\section{Identification of Extracted Colors}

Food colors were analyzed at all levels of complexity, ranging from the cursory examination for confirmation of identity, to the exhaustive purity determinations. Food colors were extracted from food materials including candies, chewing gum, sweets, ice-lollies, ice creams, soft drinks, snack products and colored beverages consisted of gola-gandas, sherbets, carbonated and other drinks sold on vending carts (thelas) that have been identified qualitatively by UV-visible Spectrophotometer (PharmaSpec UV-1700 Series, Shimadzu Corporation) using AOAC (2000) method and Pearson's Composition \& Analysis of Foods (1989). The purity test of the colors was carried out by preparing a neutral solution of the dye at a concentration suitable for spectrophotometric analysis $(0.001-0.01 \%)$. The solution is divided into three portions; to one portion a few crystals of ammonium acetate were added; to the second and third portions dilute hydrochloric acid and dilute sodium hydroxide was added, respectively, to make them $0.1 \mathrm{~N}$. The spectrophotometric curves of these solutions were determined and compared with the corresponding standard curves under the same conditions. The distinguishing features of these spectra may be significantly affected by careful adjustment of the $\mathrm{pH}$ of the colored solution towards acidic or alkaline, thus providing a valuable additional degree of discrimination. Tables $2 \& 3$ show the available standard food and textile colors, respectively, used as standard against which the samples were tested.

Table 3. List Of Textile Colors

\begin{tabular}{ll}
\hline S. \# & Textile Colors \\
\hline 1. & TC Yellow \\
2. & TC Red \\
3. & TC Blue \\
4. & TC Black \\
\hline
\end{tabular}

\section{RESULT AND DISCUSSION}

Traditionally, colorants are used to improve the appearance of different food products and to promote appetite and selling. Food selections are strong markers of age, ethnic group and class; for instance, young children prefer strong bright colors, and this extends to their choices of sweets and desserts. By adolescence, color preference has changed to pastel shades. The child view of foods is of sensory reinforcement and fun, while the adult view tends strongly 
towards health and other adult-oriented messages. The research on food additives particularly relating to colorants is very important because food is one of the most fundamental needs of man to sustain life that's why it should be fresh and free from hazardous matter particularly the sub-standard food colors and/or additives which have been frequently used in food items such as many unpacked food consisting of snacks, colored candies, bakery products, chewing gums, colored ice balls and cold drinks containing prohibited colors and toxic chemicals or additives and are usually vended outside educational institutes or in other areas inhabited by low income populations. There is no quality control in such products and the quantity of the colors and additives is generally higher to the toxic levels, even if the colors used are permissible colors or additives, compromising human health to serious diseases, resulting to an indirect financial burden over national economy. Results of the study revealed that $11 \%$ of branded and $44 \%$ of unbranded food items were unfit for human consumption respectively, whereas $16 \%$ of branded and $10 \%$ of unbranded items having either natural colors or the colors for which standards were not available (Fig. 3). Similarly 4\% of branded and $30 \%$ of unbranded beverages were unfit, whereas $3 \%$ samples having either natural or those colors whose standards were not available (Fig. 4).

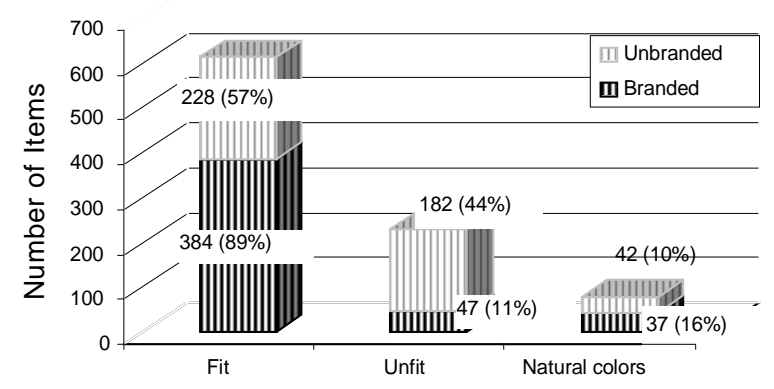

Figure 3. Analysis of Colors in Food Items

Table 1 shows the list of permissible food colorings that are approved by Pakistan Pure Food Rules 1965 (P.F.R) for the use in different food products in Pakistan; but if they are not used according to safety regulations as permitted by FDA (Table 4) then they may cause certain health threatening effects on an individual as they are reported to cause some serious diseases. It was observed that tartrazine and sunset yellow were the most common permitted colors used in various food products. The overall pattern of the frequency of the permitted food colors showed that tartrazine in blend with brilliant blue FCF is the most widely used color indicated in a variety of colored food items, followed by sunset yellow (in blend with ponceau 4R, erythrosine and carmosine), carmosine, ponceau $4 \mathrm{R}$, brilliant blue FCF (in blend with erythrosine and tartrazine).

Table 5 shows the list of food colors permitted by EU (European Union) system in which many of the food colors show over lapping as they are present in one or more than one system of regulations. While using the permissible colors in foods, the international system of regulations must be followed to assure the implementation of safety strategies, as required.

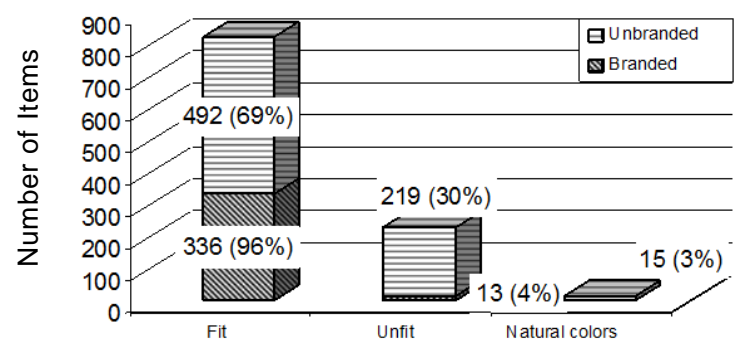

Figure 4. Analysis of Colors in Beverages

Results show that the colors that are widely used in our food items and beverages are mostly synthetic. Branded items contain permissible food colors while the samples manufactured locally in unorganized sector were found to contain undesirable quantities of food colors. In the examined samples, the colors which were found as permitted food colors were Ponceau 4R, Sunset yellow, Amaranth, Blue FCF, Tartrazine (Table 4 and 5) whereas Congo Red, Metanil yellow, Orange 11 were identified as non-permitted food colors found in different low-grade and cheap food products.

There is a dire need to create awareness at different levels about the toxicity of food colors both the use of non-permitted colors or excessive use of permitted food colors. During the 1970s, many cases of Tartrazine sensitivity were reported. Tartrazine (FD \&C Yellow No.5) is an approved azo dye present in many food products; its sensitivity is most frequently manifested by urticaria and asthma, the mechanism of sensitivity is obscure and is called pseudo allergy [23]; the management of pseudo allergy consists mainly of avoidance of food products that contain tartrazine. It has been reviewed that azo dyes (Amaranth, Ponceau SX, Allura Red, Sunset yellow, and Tartrazine) that are widely used can be reduced to aromatic amines by the intestinal micro flora and hence causes intestinal cancer [24]. In the present study, the branded food items showed satisfactory results in which only $11 \%$ of the 
food samples and 4\% of beverages were unfit whereas unbranded foods and beverages showed alarming results, that is $44 \%$ of food items and $30 \%$ of beverages were unfit for human consumption (Fig. 3 and 4). The regulation of the consumption of food permissible dyes is very important because only the application of permissible amount of these dyes in food products is not sufficient to meet the safety strategies, but consumption of colored food products should also be within limits. There are evidences which show that the over consumption of these dyes leads to health hazards [25]. A report on carcinogenesis [26] stated that the metabolism of azo dyes derived from benzidine converted to aromatic amines by intestinal bacteria is potentially carcinogenic. Azo dyes (methyl orange, methyl red, methyl yellow, Ponceau 4R, Ponceau SX, red 2G, sunset yellow, tartrazine, acid yellow, and amaranth) are widely used in textile industry, printing, cosmetics, drugs and food industries. Since intestinal cancer is more common in highly industrialized countries a possible connection may exist between the increase in the number of cancer and the use of azo dyes $[27,28]$.

Table 4: (FDA) Color Additives Certifiable For Food Use

\begin{tabular}{lll}
\hline S.\# & Color Additive & Common Name \\
\hline 1 & FD\&C Blue No.1 & Brilliant Blue FCF \\
2 & FD\&C Blue No.2 & Indigotine \\
3 & FD\&C Green No.3 & Fast Green FCF \\
4 & FD\&C Red No.40 & Allura Red AC \\
5 & FD\&C Red No.3 & Erythrosine \\
6 & FD\&C Yellow No.5 & Tartrazine \\
7 & FD\&C Yellow No.6 & Sunset Yellow \\
\hline
\end{tabular}

According to a report recently published in Current Sciences [29] some synthetic dyes like auramine, metanil yellow, lead chromate, rohdamine, sudan-3 and 4, orange- 2 and malachite green pose serious health hazards being mutagenic and potentially carcinogenic. Metanil yellow, the most frequently used nonpermitted food color widely used in food items, like "ladoos", causes insufficient oxygen supply to skin and mucous membranes along with degenerative changes in the stomach, liver, kidney, abdomen and testes and also found to cause cyanosis [13]. Another report proves that the consumption of food color Red No. 3, that has estrogen like growth stimulatory properties, may be genotoxic and could be a significant risk factor in human breast cancer [29].

It has been reported that of all the additives, dyes were the most genotoxic. Amaranth, Allura Red, New Coccine, Tartrazine, Erythrosine,
Phloxine and Rose Bengal induced dose-related DNA damage in the glandular stomach, colon, and/or urinary bladder [30]. The acceptable daily intake (ADI) levels recommended by the joint FAO/WHO Expert Committee on Food Additives [18] for amaranth and allura red are 0.5 and 7 respectively, because these dyes were tested and found responsible for the induction of DNA damage, mainly in colon [31]. Some food color additives pose a potential risk to the public health and are prohibited in food items and such color additives include FD\&C Red No. 4 [32]. The use of amaranth as a food additive has not been permitted in the United States since 1976 [33]. Human carcinomas of the gastrointestinal tract have high incidence and mortality rates, and colorectal cancer incidence become much higher in recent years, suggesting environmental causes [34].

Table 5: List Of Certified Food Colors According To InsNumber (International Numbering System For Ingredients) Eu System

\begin{tabular}{lll}
\hline S.\# & E. Number & Common Name \\
\hline 1 & E102 & Tartrazine $*$ \\
2 & E104 & Quinoline Yellow *** \\
3 & E110 & Sunset Yellow $*$ \\
4 & E122 & Carmosine *** \\
5 & E123 & Amaranth ** \\
6 & E124 & Ponceau 4R *** \\
7 & E127 & Erythrosine $*$ \\
8 & E131 & Patent Blue V $* *$ \\
9 & E132 & Indigo Carmine* \\
10 & E142 & Green S $*$ \\
11 & E151 & Black PN ** \\
12 & E107 & Yellow 2G *** \\
13 & E128 & Red 2G $* * *$ \\
14 & E133 & Brilliant Blue FCF* \\
15 & E154 & Brown FK **** \\
16 & E155 & Brown HT ** \\
17 & E180 & Rubine BK *** \\
$*$ Permissible Food color found in FDA \& EU system and P.F.R \\
$* *$ Permissible Food color found in both P.F.R \& EU system \\
$* * *$ Permissible Food color found in EU system only \\
$* * * *$ Permissible Food color found in P.F.R only \\
\end{tabular}

Few samples show the presence of natural colors, which is significant from safety point of view because natural colors are safer to use in foods as compared to synthetic colors. Currently the use of natural colorants is limited due to their instability, low tinctorial power or price disadvantage. There is a need to change the trend towards the use of natural colorants, though it totally depends upon the consumer demand, as many regulatory bodies have banned the use of some of the synthetic dyes in foods. Evidence reported for Amaranth and Tartrazine induce immunosuppressive effects in an individual that cytotoxic effects of these substances were studied in human PBL by colorimetric method in 
vitro cytotoxicity assays; the results showed clear immunosuppressive effects from the two substances tested [6]. In Pakistan, there is no awareness among the people about health hazards of food colors. Using synthetic colors may not be a problem if certain control measures are taken to keep and maintain proper regulation over the use and consumption of these dyes in foods and to discourage the use of non edible (artificial/textile colors) in food as they are life threatening when consumed.

\section{CONCLUSION}

The results of this study revealed that the quality of the products meant for local markets is highly unsatisfactory and there is a dire need to make legislation, in this regard, at provincial and national levels, and to enforce and implement those regulations on the manufacturers of such products to ensure the provision of good quality of food products meant for the low income population of the country. The assessment of information related to food color additives and public awareness is lacking in our country because of limited number of investigations as well as the poor information management and exchange activities but this lack of management can be improved by compiling a database to identify the problems of food related to color additives, quality and safety strategies. Moreover, bright and rich colored as well as unbranded food items should be avoided. Furthermore, use of food grade colors not only should be enforced strictly but their consumption should be controlled in order to get prevention from their hazardous effects. Prevention is better than cure; but, this could only be possible when each and every individual have some awareness about what he or she is going to take as a "FOOD" and it is a desired duty of both the parents and teachers to keep the children aware for what they are eating and what they have to eat especially during lunch hours in school and they should take their lunch form home rather then to buy from school canteen or from a vender out side their schools.

\section{REFERENCES}

1. Agarwal SR (1990) Prospects for small scale biscuit industry in the nineties. Indian Food Industry. 9:19-21.

2. Agarwal SR (1994) Current and future trends of biscuit industry in India. Indian Food Industry. 13:32-37.
3. Alagh KS (1990) Biscuit industry in India future scenario. Indian Food Industry 9, 18. Food and Chemical Toxicology. 20:9-14.

4. Chowdhry S (1990) Bread industry in India looking ahead. Indian Food Industry. 9:22-23.

5. Sharma I, Sharma S (1994) Prevalence of Readyto-Eat Food Intake among Urban School Children in Nepal and its Impact on Nutritional Status and Behavior. Doctoral Thesis. Delhi: Delhi University.

6. Koutsogeorgopoulou L, Maravelias C, Methenitou G, Koutselinis A (1998) Immunological aspects of the common food colorants, Amaranth and Tartrazine. Department of Forensic Medicine and Toxicology. School of Medicine. Athens. Greece.

7. NIN (1994) Studies on newer adulterants and contaminants. Annual Report 1993-94 of the National Institute of Nutrition. Hyderabad: Indian Council of Medical Research.

8. Achaya KT (1984) In: Everyday Indian Processed Foods. National Book Trust. Delhi. 154-162.

9. Rao BN (1990) Food additives - consumer's viewpoint. Indian Food Industry.9: 14-19.

10. Prasad M, Rastogi PB (1982) Effect of feeding a commonly used non-permitted colour orange II on the hematological values of Mus musculus. Journal of Food Science and Technology. 19: 150-153

11. Singh RL, Khanna SK, Singh GB (1987) Acute and short-term toxicity studies in orange II. Veterinary Human Toxicology. 29:300-304.

12. Wess JA, Archer DC (1982) Disparate in vivo and in vitro immuno-modulatory activities of Rhodamine B. Food and Chemical Toxicology. 20: 9-14.

13. Chandra SS, Nagaraja T (1987) A food poisoning outbreak with chemical dye-an investigation report. Medical Journal of Armed Forces India. 43:291-293.

14. Power JP, Barnes RM, Nash WC, Robinson JD (1969) Lead poisoning in Gurkha soldiers in Hong Kong. British Medical Journal. 3: 336-337.

15. Sachadeva SM, Mani KS, Adaval SK, Jalpota YP, Rasela KC, Chadha DS (1992) Acquired toxic methaemoglobinaemia. Journal of Association of Physicians India. 40: 239-240.

16. Lockey SD (1977) Hypersensitivity to tartrazine (FD \& C Yellow \# 5) and other dyes and additives present in food and pharmaceutical products. Annals of Allergy. 38: 206-210.

17. Padmaja R, Jonnalagadda PR, Ramesh VB. A (2004) Nadamuni Naidu Type, extent and use of colours in ready-to-eat (RTE) foods prepared in the non-industrial sector - a case study from Hyderabad, Indian International Journal of Food Science \& Technology 39. (2): 125-131

18. JECFA (1996) Summary of Evaluations Performed by the Joint FAO/WHO Expert Committee on Food Additives. 1956-1996. FAO/IPCS/WHO. Geneva: WHO. 
19. Larsen JC (1991) Erythrosine toxicological evaluation of certain food additives and contaminants. 37 th meeting of JECFA-WHO. Food Additives Series. 28: 171- 180.

20. NIIR Board of Consultants and Engineers (2004) Analysis of synthetic food colors. In; Food Colors, Flavors and Additives Technology. National Institute of Industrial Research. Dehli7, India. 170-202.

21. Ronald SK, Ronald S (1989) Food Additives. In; Pearson's Composition and Analysis of Foods, 9th (Ed.). UK. 65-139.

22. AOAC (2000) Food Color Additives. In; Official Methods of Analysis. Association of Official Analytical Chemists Inc. Gaithers Burg. USA.

23. Dipalma JR (1990) Tartrazine sensitivity. Hahnemann University School of Medicine, Philadelphia, Pennsylvania. PMID: 2239641

24. Chung KT, Stevens SE Jr (1978) Reduction of azo dyes by intestinal anaerobes. Appl. Environ. Microbiol. PMID: 25047

25. Borzelleca JF, Olson JW, Reno FE (1989) Lifetime toxicity/carcinogenicity study of FD \& C red No. 40 (allura red) in Sprague-Dawley rats. Food Chem. Toxicol. 27:701-705.

26. Combes RD, Haveland-Smith RB (1982) A review of the genotoxicity of food, drug and cosmetic colors and other azo, triphenylmethane and xanthene dyes. Mutat Res. 98: 101-248

27. Chung, KT, Stevens SE Jr, Cerniglia CE (1983) The significance of azo reduction in the mutagenesis and carcinogenesis of azo dyes. Mutat Res. PMID: 6339890
28. Chung KT, Cerniglia CE (1992) Mutagenicity of azo dyes: Structure-activity relationships. Mutat Res. 277: 201-220.

29. Dees C, Askari M, Garrett S, Gehars K, Henley D, Ardies CM (1997) Environ Health Perspect, Estrogen and DNA-damaging activity of Red No.3 in human breast cancer; Health Sciences Research Division, Oak Ridge National Laboratory, Tennessee, USA.

30. Sasaki YF, Kawaguchi S, Kamaya A, Ohshita M, Kabasawa K, Iwama K, Taniguchi K, Tsuda S (2002) The comet assay: results with currently used food additives. Laboratory of Genotoxicity. Faculty of Chemical and Biological Engineering. Hachinohe National College of Technology. Japan.

31. Ito Y (2000) Recent state and the investigation of daily intake of food additives in Japan-21 years.

32. Food and Color Additives. Ch. 19. In; Fish and Fishery Products Hazards and Controls Guidance. 3rd ed. Food and Drug Administration, Center for Food Safety and Applied Nutrition, Office of Seafood. Washington. 2001: 237-248.

33. Prival MJ, Davis VM, Peiperl MD, Bell SJ (1988) Evaluation of azo food dyes for mutagenicity. 206: 247-259.

34. Goldin-Lang P, Kreuser ED, Zunft HJ (1996) Basis and consequences of primary and secondary prevention of gastrointestinal tumors. Recent Results Cancer Res.142: 163-192. 